Vol. 4, No. 1, 2019

\title{
DETECTION OF CYANOTOXINS IN LAKE TORMENT (NOVA SCOTIA, CANADA)
}

\author{
Kateryna Hushchyna, Kayla McLellan, Tri Nguyen-Quang \\ Biofluids and Biosystems Modeling Lab (BBML) \\ Faculty of Agriculture, Dalhousie University, \\ 39 Cox Road, B2N 5E3, Truro-Bible Hill, \\ Nova Scotia, Canada \\ tri.nguyen-quang@dal.ca
}

https://doi.org/10.23939/ep2019.01.045

Received: 10.03.2019

(C) Hushchyna K., McLellan K., Nguyen-Quang T., 2019

\begin{abstract}
This paper will update some information related to cyanotoxins detected in lake Torment, a recreational freshwater body in Nova Scotia, Canada. The goal of our paper is to present the detected toxins released by Toxic Algal Blooms and introducing the method of measurement by using the ELISA test. The results can show a very potential approach of toxin detection which could be applied in Ukraine or other countries where cyanotoxin detection in fresh and marine water ecosystems are still not well developed.
\end{abstract}

Key words: Lake Torment, Cyanobacterial blooms, Cyanotoxins, Microsystins, Anatoxin-a, ELISA test.

\section{Introduction}

Lake Torment is located in Kings County, Nova Scotia, Canada (Fig. 1), belonging to the LaHave River watershed system. There is a series of three interconnected lakes in this system: Chain lake from the upstream which drains into Armstrong lake, the second drains into lake Torment, which is quite deep on the South part with thin sediment layer at the bottom. The more oriented to the South, the deeper bottom configuration which is normally shallow and rocky at the North. The lake is used for residential and recreational purposes. It is surrounded by forests and no agricultural activity nearby. Lake Torment is a dystrophic lake with brown water, low $\mathrm{pH}$, low carbonate level and high organic contents [1]. The apparition of algal blooms in lake Torment was seriously mentioned since 2014. However, there was no previous study as well as a monitoring program about water quality in this watershed till 2014. In 2014-2015, some nutrient measurements but no data connecting to biological parameters except for some rare chlorophyll-a values (once a month at one deep location) are monitored by Kings County [1,2]. Our Biofluids and Biosystems Modeling Lab (BBML) was involved in the study of cyanobacterial blooms in lake Torment since 2015, when Dolichospermum flos-aquae in high biomass was identified [3], but the systematic monitoring was officially organized by our Lab since 2017 [4].

The surface bloom apparition was random from June to November and the number of bloom episodes increased from 2014 to 2017 when our monitoring program was established. As blooms were created by Dolichospermum flos-aquae, which is considered as potentially toxic (producer of microcystins, anatoxins and some tiny amount of saxitoxins), a program for cyanotoxin monitoring is an indispensable step.

Microcystins are cyclic peptides (hepatotoxin) and the main freshwater toxin which mostly produced by Microcystis sp., but it could be found in blooms of Anabaena sp. (Dolichospermum sp.), Planktothrix, Oscillatoria sp. [5]. This family of toxins is intracellular, i.e. only being released during the cell death and destruction.

Anatoxin is a group of alkaloids, classified as neurotoxins. It can be found mostly in Anabaena sp. blooms [5]. But the phylum of Oscillatoria, Aphanizomenon and Cylindrospermum can also release this toxin in the water [6].

There are several methods that are commonly used in microcystin and anatoxin detection, including commercial enzyme-linked immunosorbent assays and liquid chromatography (LC) coupled with electrospray ionisation and different mass analysers [7, 8]. Mirocystins can be detected by protein phosphatase inhibition assays and reversed phase high performance liquid chromatography (HPLC) as well [7]; while for 
anatoxins other methods are applied such as colorimetric receptor-binding assay and GS-MS [8]. Liquid Chromatography-Mass Spectrometry LC-MS/(MS) is the best approach to detect cyanotoxins, but the cost of the equipment and reagents is very high. Therefore, the LC-MS/(MS) does not allow a wide use in cyanotoxin determination/detection around the world, especially in the developing and underdeveloped countries. The Enzyme-linked Immunosorbent Assays (ELISA) are otherwise a cheaper alternative for the screening of big number of samples in short time to get reliable quantitative results. Unfortunately, for microcystins, ELISA cannot distinguish the type of microcystins, as it could help identify only the total microcystin content.

Due to its reasonable cost and user-friendly technique, the ELISA kits (Warminster, PA, USA) become a 'quick' and useful test to detect certain cyanotoxins. The aim of this paper is to show the application of ELISA kits as an easy detection method during and after cyanobacterial blooms. Moreover, this paper will contribute to the scientific literature as the first publication about toxin production of cyanobacterial blooms (Dolichospermum flos-aquae) in acidic lakes in Nova Scotia province.

\section{Methodology}

\subsection{Field sampling locations and Lab analysis}

Sampling took place during 2016-2018, mostly connecting to the bloom period. Sample locations and their coordinates are in Fig. 1 and Table 1.

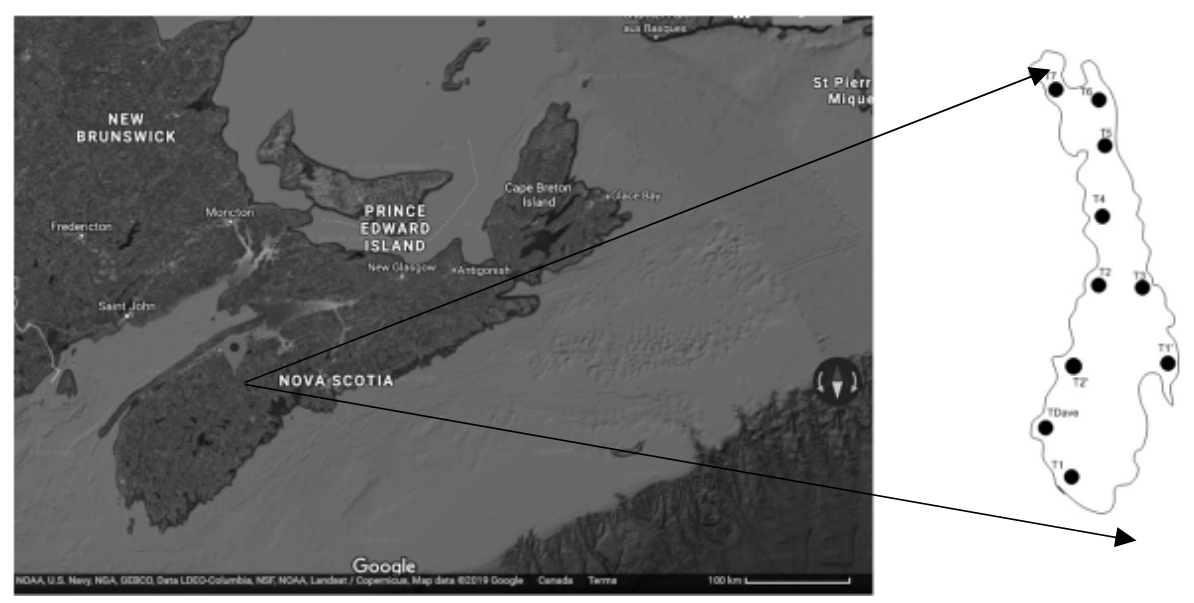

Fig. 1. Lake Torment sampling maps

Coordinates of sampling locations in Lake Torment

\begin{tabular}{|c|c|c|c|c|}
\hline \multicolumn{5}{|c|}{ Lake Torment } \\
\hline Location & N-Coordinate & W-Coordinate & N-Coordinate & W-Coordinate \\
\hline \multicolumn{5}{|c|}{$\mathbf{2 0 1 6 - 2 0 1 7}$} \\
\hline T1 & 44.71798 & 064.74467 & 44.71798 & 064.74467 \\
\hline T1' & - & - & 44.72619 & 064.73376 \\
\hline T2 & 44.72710 & 064.74387 & 44.72710 & 064.74387 \\
\hline T2' & - & - & 44.72713 & 064.74450 \\
\hline T3 & 44.72715 & 064.73530 & 44.72715 & 064.73530 \\
\hline T4 & 44.73933 & 064.74036 & 44.73933 & 064.74036 \\
\hline T5 & 44.74369 & 064.73926 & 44.74369 & 064.73926 \\
\hline T6 & 44.74960 & 064.74142 & 44.74960 & 064.74142 \\
\hline T7 & 44.75008 & 064.74615 & 44.75008 & 064.74615 \\
\hline T8 & 44.75116 & 064.74110 & & 064.7481 \\
\hline T9 & 44.74580 & 064.73930 & & \\
\hline T10 & 44.74213 & 064.74172 & & \\
\hline T Dave & 44.72186 & 064.74819 & 44.72186 & \\
\hline
\end{tabular}


The following is general monitoring steps processed from our Lab for lake and reservoirs, including:

1. Sampling of the lake at least once a month;

2. The field parameters are measured for $\mathrm{pH}$, temperature, dissolved oxygen (DO in $\mathrm{mg} / \mathrm{L}$ and \%), conductivity at the surface $(0.5 \mathrm{~m})$ and bottom levels $(1 \mathrm{~m}$ above the bottom) by using YSI Probe (Professional Plus, Hoskin scientific LTD, USA); and transparency by using Secchi disk.

3. If there are blooms present at the lake/reservoir, samples will be taken for the taxonomy analysis.

4. Water was collected from two levels: surface $(0.5 \mathrm{~m})$ and bottom $(1 \mathrm{~m}$ above the bottom) in duplicate samples (location in Fig. 1);

5. Different nutrient analyses included phosphatephosphorus, total phosphorus, ammonium, nitrate+nitrite, silica, total iron, chlorophyll-a, phycocyanin.

6. Water samples from blooms and after bloom period were analysed for microcystins and anatoxin-a.

In the context of this paper, we would just describe the analysis conducted for cyanotoxins. Nutrient analysis and all other field measurements such as Secchi disk depth or dissolved oxygen (DO), etc. will not be mentioned here.

\subsection{Principle and process of toxin analyses by ELISA tests}

The principle of ELISA test is based on the competition of binding for toxins and enzyme conjugate (microcystin or anatoxin-a) to the anti-microcystin (or anti-anatoxin) antibodies in solution and then binding to the goat anti-mouse antibody which coated the wells. Substrate solution works on the color development. The intensity of color is inversely proportional to the concentration of microcystins or anatoxin-a. The absorbance was read at $450 \mathrm{~nm}$ using a microplate reader (Thermo Scientific, USA) (Fig. 2). The quantified concentration based on MC-LR/ anatoxin-a standards and by 4-parameter evaluation. Limit of detection is $0.15 \mu \mathrm{g} / \mathrm{L}$.

The advantage of this method is the use of direct water sampled from the lake. For anatoxin-a, water samples from the field were preserved by adding provided diluent from the kit to slow down the degradation of anatoxin-a as this process is very rapid [6]. All samples were kept in $-20{ }^{\circ} \mathrm{C}$ freezer until the day of measurements. The plate consists of 96 wells. Standards for MC-LR/Anatoxin-a are used for quantification of microcystins. In total 38 samples in duplicate (25 in triplicate) can be analysed at once. Three times freeze-thaw cycles were used to lyse the cells, which is the requirement if we need to detect the total toxin content in the water. These toxins are intracellular origin, i.e. the toxin remains inside of the cell until the cell lysis. After the cell breaking down, samples were filtered using GF/C filter to remove all particulate material. All samples were processed according to the Abraxis instructions. Briefly, the principle and procedure to measure microcystins and anatoxin-a by ELISA test are explained in Figs. 2-3 below.

The Microcystins Adda-DM ELISA kit can analyse the total amount of microcystins and nodularins in the water. The principle is based on the recognition of the Adda branch of the toxins. One of the disadvantages for this strategy is that non-toxic Adda appearing in the water after the microbial degradation of toxin can be still detected, i.e. results could be overestimated [9]. The ELISA kit for anatoxin-a measures only anatoxin-a content in the water samples.

The procedure to measure cyanotoxins according to Abraxis's instruction is shown in Fig. 3, for only anatoxin-a and total microcystins. All steps were processed following the provided procedure from the company. Briefly, for microcystins, $100 \mu \mathrm{L}$ of the standard solutions, control, or samples were added to the appropriate wells. Analysis of standards were in triplicate and samples in duplicate. $50 \mu \mathrm{L}$ of the enzyme conjugate solution was added to all of the wells, followed by addition of $50 \mu \mathrm{L}$ of the antibody solution. Incubation of the plate for 90 minutes at room temperature was done. Three times washing with at least $250 \mu \mathrm{L}$ of wash buffer for each time was used. Next $150 \mu \mathrm{L}$ of substrate (color) solution was added to all the wells and after 20-30 minutes of incubation at the room temperature, $100 \mu \mathrm{L}$ of stop solution was added. Absorbance at $450 \mathrm{~nm}$ using a Multi-scanner FC (Thermo Scientific, USA, Fig. 2) was done within 15 minutes of adding the stop solution. The procedure for axatoxin-a, quite similar, is also shown in Fig. 3.
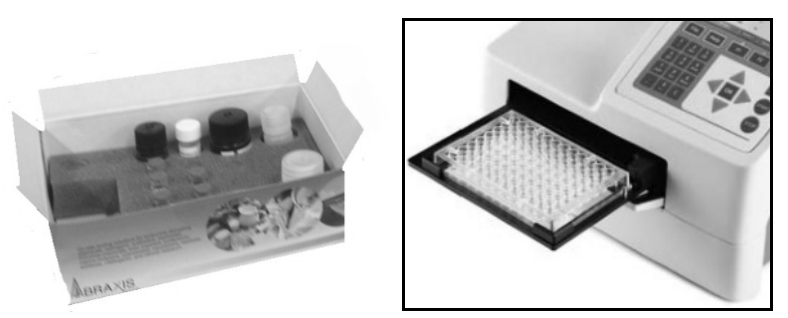

Fig. 2. Left: ELISA kit; and Right: 96 well plate with Plate scanner (Microplate reader) used for the toxin analysis 


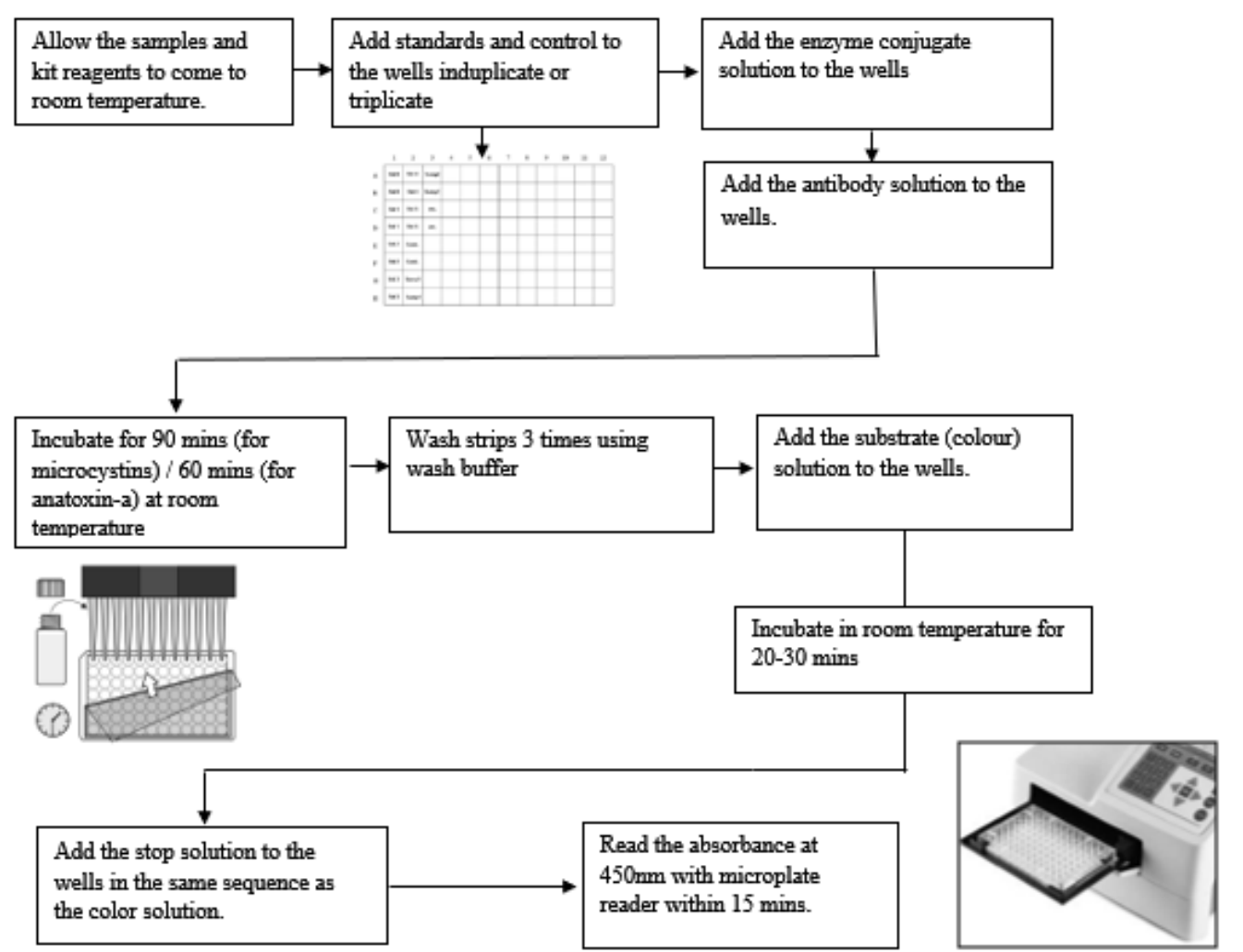

Fig. 3. The general procedure for both Anatoxin-a and Total Microcystins by ELISA tests

\section{Results and discussion}

In a general view of cyanotoxin detection for lake Torment, we started analyses of microcystins from 2016-2018, and of anatoxin-a data from 2016-2017 (Table 2 below). Although we measured all of samples collected accordingly to the plan shown in Fig. 1, most of the data presented herein were from Dave's Cove (a permanent resident of lake Torment), where the environmental conditions favored the accumulation and aggregation of cyanobacterium. Dolichospermum flosaquae was identified as responsible for all bloom episodes from May to November in 2016-2018. Only in late fall blooms in 2017 Microcystis aeruginosa, another cyanobacterial species, was co-identified with high biomass (Fig. 4). The bloom apparition in lake Torment is different from year to year, but it could be summarized into five scenarios for 2017-2018: May and/or early June, late June, August, September; and October blooms. The latter can persist until the middle of November.

The results of total microcystins and anatoxin-a are in Table 2. In Canada, there exists only the regulation related to microcystins for drinking and recreational water. For drinking water, the regulation is $1.5 \mu \mathrm{g} / \mathrm{L}$ of microcystin-LR [10] and for recreational waters, this limit becomes $20 \mu \mathrm{g} / \mathrm{L}$ of total microcystins [11]. Anatoxin-a is only regulated in the province of Quebec
[12] where the limit for drinking water is $3.7 \mu \mathrm{g} / \mathrm{L}$ and for recreation $40 \mu \mathrm{g} / \mathrm{L}$.
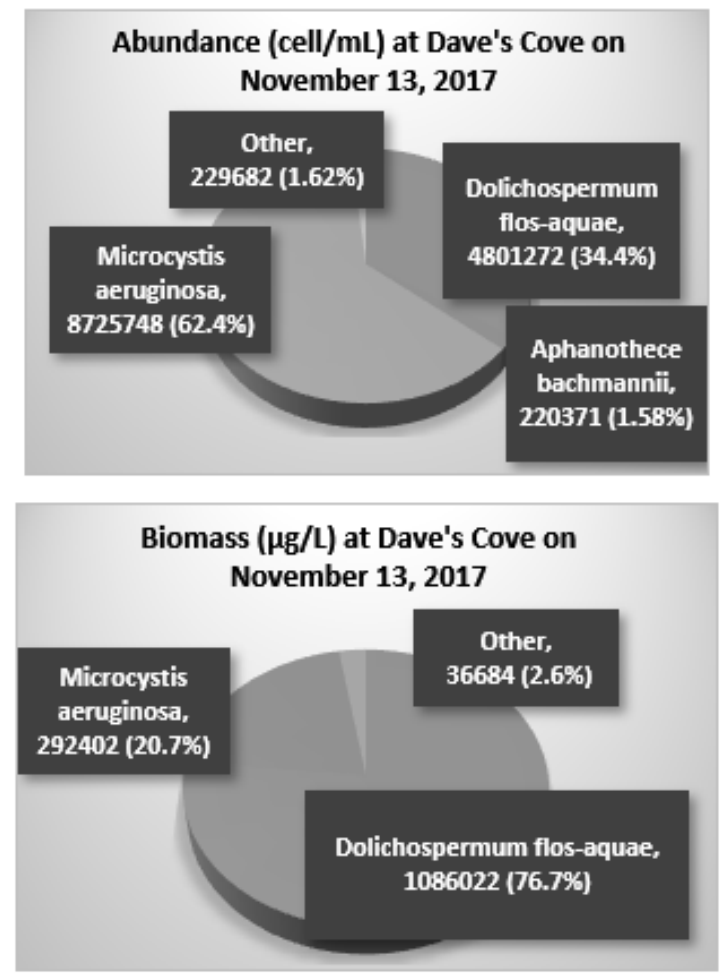

Fig. 4. Taxonomy results from Dave's cove on November 13, 2017 
The analyses of the data 2016-2018 show that all microcystin concentrations closer to $1.5 \mu \mathrm{g} / \mathrm{L}$ appeared only at the end of August and increased rapidly in the fall season. Even though lake Torment is a recreational waterbody, concentrations of microcystins are detected very close to drinking water regulation, therefore dangerous for human beings and animals in case of swallowing the lake water.

In 2018 there was a series of blooms appeared at TDave location in the end of August (27-29 August). Water was collected with the interval of 6 hours to see the dynamics of microcystins accumulation. Depending on the scum size and scale, concentrations of toxin were different. It was visually observed that the accumulation of scums appeared around noon time and persisted until the evening but disappeared in the morning, i.e. the water became clear from cyanobacterial scums at the morning time. Microcystin concentration widely varied in this context from $0.3 \mu \mathrm{g} / \mathrm{L}$ to greater than $100 \mu \mathrm{g} / \mathrm{L}$, and then decreasing (even disappearing) at night and increasing at noon.

The anatoxin-a was present with very small amounts in June 18 and August 17 2017. In 2018 no significant value of anatoxin-a was detected through all the sampling season as showed in Table 2. However, that does not mean the lake was anatoxin-free because our method with ELISA test and even with LC-MS did not reach values lower than their limits of detection.
Toxin data from 2016 to 2018

\begin{tabular}{|l|l|c|c|}
\hline \multicolumn{1}{|c|}{ Location } & \multicolumn{1}{|c|}{ Date } & $\begin{array}{c}\text { Microcystins, } \\
\mu \mathrm{g} / \mathrm{L}\end{array}$ & $\begin{array}{c}\text { Anatoxin-a, } \\
\mu \mathrm{g} / \mathrm{L}\end{array}$ \\
\hline TDave & November 16, 2016 & $<0.15$ & $<0.15$ \\
\hline TDave & June 18, 2017 & 0.74 & 0.35 \\
\hline T1'bottom & June 24, 2017 & $<0.15$ & $<0.15$ \\
\hline T7 bottom & June 24, 2017 & 0.24 & $<0.15$ \\
\hline TDave & August 17, 2017 & - & 0.32 \\
\hline TDave & August 29, 2017 & $>5.0$ & $<0.15$ \\
\hline TDave & September 9, 2017 & 0.94 & - \\
\hline TDave & September 16, 2017 & $>25$ & - \\
\hline TDave & August 27, 2018 6pm & 1.32 & - \\
\hline TDave & August 28, 2018 noon & $>100$ & - \\
\hline TDave & August 28, 2018 6pm & 0.34 & - \\
\hline TDave & August 29, 2018 6am & 0.67 & - \\
\hline $\begin{array}{l}\text { TDave } \\
\text { surface }\end{array}$ & August 29, 2018 noon & 2.01 & - \\
\hline $\begin{array}{l}\text { TDave } \\
\text { bottom }\end{array}$ & August 29, 2018 noon & 0.65 & - \\
\hline TDave & October 4, 2018 & 12.2 & - \\
\hline TDave & November 15, 2018 & $<0.15$ & - \\
\hline
\end{tabular}

“-” : samples were not measured for that toxin

Some interesting events recorded for cyanotoxin detection at Dave's cove are hereby described (Fig.5).

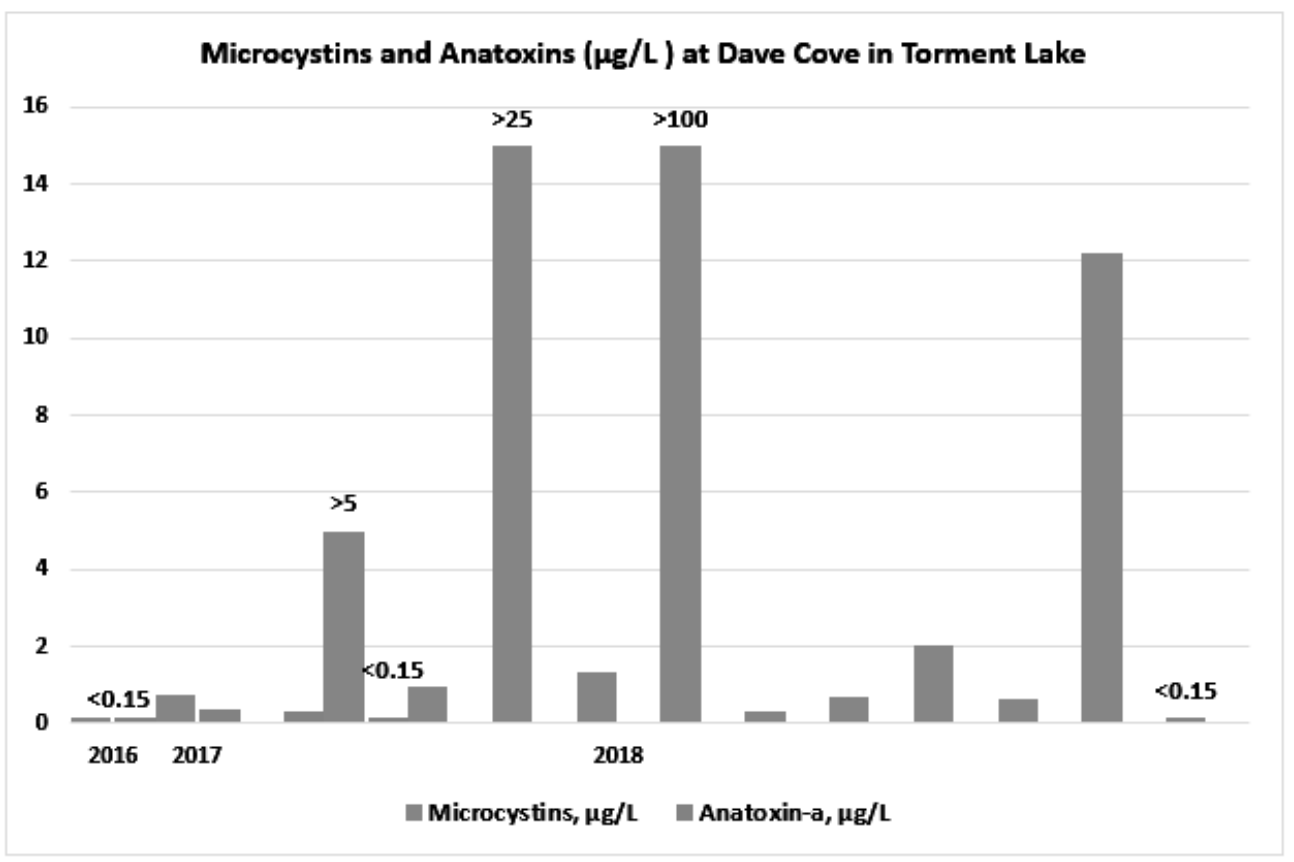

Fig. 5. Microcystins and Anatoxin-a detected in Dave Cove from 2016 to 2018

The November 2016 samples showed a concentration of microcystins that was lower than the detection limit. Microcystins were present in summer 2017 samples except T1' at the bottom on June 24. In June, concentrations of microcystins were lower than $1.5 \mu \mathrm{g} / \mathrm{L}$. Samples in the end of August had concentration greater than the mean measurement range ( 1.5 to $5 \mu \mathrm{g} / \mathrm{L})$.

The same samples for microcystins and one additional one of August 162017 were also tested for the presence of anatoxin-a in the water. Only very small 
concentration of anatoxin-a (around $0.3 \mu \mathrm{g} / \mathrm{L}$ ) was detected in samples of June 18 and August 16 2017. It is interesting to note that two types of toxins were present at the same time in the water on June 182017.

In 2018, many water samples tested for microcystins presented positive results. From the bloom sample of August 27, the concentrations of microcystins were found low: between $0.1 \mu \mathrm{g} / \mathrm{L}$ and $1.32 \mu \mathrm{g} / \mathrm{L}$. The highest concentration of microcystins was found at Dave's cove on August 28 at noon, with a value greater than $100 \mu \mathrm{g} / \mathrm{L}$.

No blooms were observed in this cove after August until October $4^{\text {th }}$ 2018. Analyses of total toxins in October found microcystins $(12.2 \mu \mathrm{g} / \mathrm{L})$ without the presence of anatoxins. The increase of microcystin concentration was also observed for the 2017samples. Therefore, it is concluded that there is a tendency of the toxin growth due to strains of Dolichospermum flos-aquae in fall. Our November samples were analyzed but did show no signs of bloom accumulation, and hence toxin-free.

\section{Conclusions}

Lake Torment is an acidic lake with a $\mathrm{pH}$ around 5-6. The geology of lake bottom is poor bedrock with a low nutrient sediment content [2]. Nutrient limitation creates poor conditions for cyanobacterium growth. However, meteorological conditions are one of the reasons of Dolichospermum flos-aquae growth.

Warmer spring in 2017 gave the favor to the earlier blooms in May, while a cold spring in 2018 has postponed this event to the middle of June. The warm fall of 2017 supported the bloom growth till the end of October, while in 2018 the last bloom was observed in the beginning of October due to a cold September.

There are still many unknown relationships of toxin releases and environmental factors in the lake. That will be the next step of our research. However, it is qualitatively noticed that there is a high accumulation of microcystins in colder water (beginning of fall season) and the presence of anatoxin-a also associated with the cold water.

It is found that there is a variety of toxins with high concentration in a bloom, where we also found the presence of two main different cyanobacterial species coexisting. This cohabitation of these two species Dolichospermum flos-aquae and Microcystis aeruginosa could be the reason for different toxins detected with high concentrations.

Monitoring results from 2016-18 showed the need of further research in Lake Torment for the relationship between toxin variety and concentration associated with cyanobacterial species detected in different seasons, and how these factors can be linked to environmental conditions.
It should be noted that all these tests only reflect the conditions in the lake at the time of sampling. Prior to, or after the sampling moments, conditions are certainly not the same.

\section{Acknowledgements}

TNQ acknowledges the Natural Science and Engineering Research Council of Canada via Discovery Grant NSERC RGPIN 03796, Canada Foundation for Innovation as well as Nova Scotia Research and Innovation Trust via Grant No 31188 for equipment. We acknowledge the residents of lake Torment, especially Dave Alexander and his Spouse Dawn for their very active collaboration and assistance during our field trips. We also acknowledge BBML students (Nadeem Mohammad and Dung Tri Nguyen) for their contributions to our field trips.

\section{References}

[1] Kings County (2016). Kings County lake monitoring, 2016 season. Report. Municipality of the County of Kings, Nova Scotia, Canada.

[2] Kings County (2015). Kings County lake monitoring, 2015 season. Report. Municipality of the County of Kings, Nova Scotia, Canada.

[3] Nguyen-Quang T. (2016). Preliminary report for 3 lakes in King County - East Dalhousie (Chain Lake, Armstrong and Torment). A technical report. BBML. Dalhousie University.

[4] Nguyen-Quang T., McLellan K., Hushchyna K., Murdock A. (2018). Harmful Algal Bloom (HAB) Monitoring for Lake Torment and Armstrong Lake. A systematic investigation in 2016-2017 versus 2014 Kings County water quality results. A technical report. BBML. Dalhousie University.

[5] World Health Organization (2003). Guidelines for safe recreational water environments. Vol. 1: Coastal and fresh waters, $253 \mathrm{p}$.

[6] Chorus I. and Bartram J. (1999). Toxic Cyanobacteria: A guide to their public health consequences, monitoring and management. Routledge, London and New York, $400 \mathrm{p}$.

[7] Catherin A., Bernard C., Spoof L., Bruno M. (2017). Microcystins and Nodularins. In Meriluoto J., Spoof L., Codd G. A. (eds) Handbook of cyanobacterial monitoring and cyanotoxin analysis. Chichester, West Sussex: John Wiley \& Sons, Inc., 109-126.

[8] Bruno M., Ploux O., Metcalf J. S., Mejean A., Pawlik-Skowronska B., Furey A.: Anatoxin-a, Homoanatoxin-a, and Natural Analogues. In Meriluoto J., Spoof L., Codd G. A. (eds) Handbook of cyanobacterial monitoring and cyanotoxin analysis. Chichester, West Sussex: John Wiley \& Sons, Inc., 109-126. 
[9] Harada K., Imanishi S., Kato H., Mizuno M., Ito E., Tsuji K.K. (2004). Isolation of Adda from microcystinLR by microbial degradation. Toxicon 1, 44, 107-109. DOI: 10.1016/j.toxicon.2004.04.003

[10] Health Canada (2014). Guidelines for Canadian Drinking Water Quality-Summary Table. Water and Air Quality Bureau, Healthy Environments and Consumer Safety Branch, Health Canada, Ottawa, Ontario.
[11] Health Canada (2012). Guidelines for Canadian Recreational Water Quality, Third Edition. Water, Air and Climate Change Bureau, Healthy Environments and Consumer Safety Branch, Health Canada, Ottawa, Ontario. (Catalogue No H129-15/2012E).

[12] Chorus I. (2012). Current approaches to Cyanotoxin risk assessment, risk management and regulations in different countries. Umwelt Bundesamt, $147 \mathrm{p}$. 